\title{
CLIO NO PALÁCIO DE MINERVA: DIÁLOGOS EPISTEMOLÓGICOS
}

\author{
Antônio Roberto Xavier ${ }^{1}$ \\ Eduardo Ferreira Chagas ${ }^{2}$ \\ Sídney Guerra Reginaldo ${ }^{3}$
}

Resumo:

Este artigo parte do pressuposto de que o debate sobre se a História é Ciência é sempre atual e necessário. Desse modo, esta escrita tem por objetivo principal explicitar as principais concepções e acepções sobre História e Ciência na perspectiva teórico-metodológica do conhecimento. Para tanto, buscou-se fundamentação em fontes secundárias de livros e artigos de periódicos científicos que abordam qualitativamente as principais categorias expostas no título desta pesquisa de cunho teórico-bibliográfico. No tocante à interpretação das fontes, aplicou-se a análise do conteúdo e do discurso como técnicas no âmbito de um processo histórico-dialético-crítico. Em conclusão, percebe-se que o conteúdo textual buscou atender às demandas suscitadas na problemática e no objetivo principal, visando trazer uma contribuição acadêmico-científica de forma relevante. Por fim, restou demonstrado que a História é Ciência de raciocínio e essencialmente investigativa, que busca o conhecimento das ações ou omissões dos viventes no tempo e no espaço, seus efeitos, impactos ou sentidos nos diferentes contextos da sociedade.

Palavras-chave: Ensino. História. Ciência. Conhecimento.

\section{HISTORY AND SCIENCE: EPISTEMOLOGICAL DIALOGUES}

\begin{abstract}
:
This article assumes that the debate about whether History is Science is always current and necessary. In this way, this writing has as main objective to explain the main conceptions and meanings about History and Science in the theoretical-methodological perspective of knowledge. To this end, a search was made for secondary sources of books and articles from scientific journals that qualitatively address the main categories exposed in the title of this theoretical-bibliographic research. Regarding the interpretation of the sources, it was applied to the analysis of content and discourse as techniques in the context of a historical-dialectic-critical process. In conclusion, it is clear that the textual content sought to meet the demands raised in the problem and in the main objective, aiming to bring a relevant academic-scientific contribution. Finally, it remains to be demonstrated that History is a reasoning Science and essentially investigative that seeks knowledge of the actions or omissions of those living in time and space, their effects, impacts or meaning in different contexts of society.
\end{abstract}

Keywords: Teaching. History. Science. Knowledge.

1 Pós-Doutor em Educação pela Universidade Federal do Ceará (UFC) e pela Universidade Federal da Paraíba (UFPB) e doutor em Educação pela UFC. Professor adjunto de graduação em Administração Pública e do Mestrado em Sociobiodiversidade e Tecnologias Sustentáveis (Masts), ambos da Universidade da Integração Internacional da Lusofonia Afro-Brasileira (Unilab). Líder do Grupo de Pesquisa Gestão de Políticas Sociais (GPS/Unilab/CNPq).E-mail: roberto@unilab.edu.br. http://orcid.org/0000-0002-3018-2058

2 Pós-Doutor e doutor em Filosofia pela Universität Munster (Alemanha) e pela Universidade de Kassel (Alemanha), respectivamente. Professor associado IV da graduação e pós-graduação do Departamento de Filosofia da Universidade Federal do Ceará (UFC) e colaborador do Programa de Pós-Graduação em Educação Brasileira da Faculdade de Educação (Faced) da UFC. Bolsista de Produtividade em Pesquisa do Conselho Nacional de Desenvolvimento Científico e Tecnológico (CNPq).E-mail: ef.chagas@uol.com.br. Homepage: www.efchagas.wordpress.com. http://orcid.org/0000-0003-1957-6117

3 Pós-Doutor em Educação pela Universidade Federal do Ceará (UFC) e doutor em Direito Constitucional pela Universidade de Fortaleza (Unifor) e em Sociologia pela UFC. Professor adjunto da Faculdade de Direito da UFC, do Departamento de Direito Privado e do Programa de Pós-Graduação em Educação da UFC. E-mail: sidneyguerra@ufc.br. http://orcid.org/0000-0002-0382-2275 


\section{Introdução}

A propósito de esclarecimento acerca da temática deste artigo, registramos que Clio refere-se à deusa mitológica da História e Minerva, à deusa das Ciências. Neste caso, poderíamos substituir o tema em epígrafe por "O ensino-aprendizagem da História como Ciência” e o subtema, "diálogos epistemológicos", por "teoria do conhecimento". Mas, como acentua Hobsbawm (1998), um combate permanente deve ser procedido pelos pacatos historiadores diante dos implacáveis detratores da História, pois estes estão sempre a postos para atacar seja pelo senso comum, seja pelo ranço ideológico ou até por princípios epistemológicos mal digeridos.

O problema central elencado para a produção deste artigo consiste na premissa geral de que a História ainda paga muito caro pelo fato de ter sido, por muito tempo, apropriada pelos discursos oficiais dirigentes e mal conduzida por pseudo profissionais em razão de macro teorias de eixos dominantes no campo do saber histórico.

O pressuposto inicial considera que o debate teórico, epistemológico e metodológico sobre História e Ciência é sempre atual. Parte-se da ideia de que as correntes ou vertentes dessas categorias continuam sendo matérias de profundas e expansivas discussões, sobretudo no âmbito acadêmico. O debate sobre esses aportes é indispensável para a compreensão nos diferentes contextos do fazer-saber científico no âmbito das Ciências Humanas.

Perceber e refletir sobre as interconexões e distinções da Teoria da História, da Metodologia e da Ciência são tarefas indispensáveis para os historiadores atuais que buscam compreender a construção histórica em suas variadas e extensas nuances. Juntem-se aí os grandes "acordes historiográficos" ou paradigmas teórico-científicos da História.

Certamente, em razão de sua polissemia, a História e/ou o conhecimento histórico, ao procurar investigar cientificamente e filosofar sobre os fatos históricos, adentra(m) na seara pluralista de outras várias produções do conhecimento. Abre-se aí um leque de possibilidades de saberes, principalmente quando nos debruçamos na tentativa de compreender os significados reais e representativos desses fatos, saindo do maniqueísmo objetivista para abarcar às subjetividades inerentes aos seres humanos.

Desse modo, o conhecimento histórico apresenta-se como algo instigante, dinâmico e infindável, exigindo continuamente um exercício hermenêutico constante a partir de algumas indagações, tais como: o que é História e o que é Ciência? Qual o objeto e objetivo da História? Que História se quer abordar? Em outras palavras, seria o mesmo que dizer: quais os "domínios

\begin{tabular}{|c|c|c|c|c|}
\hline Q Rovista Qialectus & Ano 10 & n. 23 & Maio - Agosto 2021 & p. $83-104$ \\
\hline
\end{tabular}


da História?”. Esses questionamentos, doravante, conduzirão o debate teórico-metodológico e dialético com a teoria do conhecimento.

Essas indagações despertam interesses de pesquisadores, docentes, discentes e fazedores de História, seja no âmbito acadêmico, escolar ou popular (História do Cotidiano). Lembrando Bachelard (2007), o conhecimento científico só nos é possível a partir de perguntas. Nesse caso, visando a atender aos pressupostos indagativos e explicitar os principais entendimentos sobre o ensino-aprendizagem de História e Ciência, procedemos à construção deste artigo a partir de diálogos teórico-metodológicos e epistemológicos com abordagem qualitativa e análise interpretacional dialético-crítica de conteúdo e do discurso de fontes secundárias. Nesse sentido, o texto segue distribuído em tópicos.

\section{A propósito de/da ciência}

O debate teórico-metodológico e epistemológico sobre História e Ciência, na perspectiva do ensino-aprendizagem, continua latente. Invertemos as categorias de análise trazendo a categoria Ciência para o debate neste tópico para, em seguida, adentrarmos na seara da categoria História. O pressuposto inicial em relação à definição de Ciência é que esta é investigação sobre um objeto de pesquisa visando a uma explicação plausível, testável, justificável, replicável, racionalmente validável, fundamentada em teoria, observação e/ou experimentação.

Todavia, os conceitos e definições acerca do vocábulo "Ciência" têm se modificado ao longo do tempo. Por exemplo, a definição tradicional de Ciência incluía a garantia absoluta de validade ao conhecimento aplicável. Do contrário, na modernidade, a validade do conhecimento aplicável ocorre em qualquer forma ou medida. Não há essa exigência do absoluto no conhecimento científico. Aliás, na concepção contemporânea, ao invés de absoluta e inquestionável, uma das características da Ciência é a refutabilidade ou falseabilidade (ABBAGNANO, 1998; POPPER, 1982).

Entretanto, até o advento da modernidade, a Ciência e a Filosofia caminhavam em uma só determinante, ou seja, considerava-se quem era filósofo também como cientista. A ruptura dessa compreensão ocorre a partir da segunda metade do século XVI depois de Cristo (d.C.), com a concepção de Ciência iniciada por Francis Bacon, chamado de o "[...] primeiro dos modernos e último dos antigos, inventor do método experimental, fundador da ciência moderna e do empirismo [...]" (BACON, 1997, p. 5). A partir de então, sobretudo com a

\begin{tabular}{|l|l|l|l|l|}
\hline Qevista Dialectus & Ano 10 & n. 23 & Maio - Agosto 2021 & p. 83 - 104 \\
\hline
\end{tabular}


Revolução Científica do século XVII, o pensamento clássico moderno reivindica que a Ciência deve ter seu método próprio, autônomo e neutro de qualquer juízo ou prenoções sobre os objetos a serem investigados (GIL, 1999).

Etimologicamente "Ciência" deriva da palavra "scientia", originária de "scire", significando "[...] aprender ou alcançar conhecimento. É claro que a origem é muito genérica e que o vocábulo 'ciência' tal como o usamos hoje aponta para um tipo de conhecimento mais especial e apurado [...]"” (MORAIS, 1988, p. 50, grifos do autor).

A Ciência, no seu uso mais moderno pelo homem, tem a missão de validar como verdade (pelo menos parcialmente, até que descobertas de novas leis e teorias científicas venham à tona) as suas descobertas, valendo-se dos princípios da objetividade, universalidade e neutralidade científica em suas experimentações. Como produto do ser humano, é limitada, imperfeita, provisória, mutável e está em processo constante de renovação: “[...] a ciência é edifício bastante frágil: o melhor que pode alcançar é a oferta da apreciação continuamente cambiantes de como as coisas funcionam. Nosso conhecimento é sempre atacável e provisório [...]” (DEMO, 2010, p. 46).

Nos dicionários recentes, Ciência é sinônimo feminino que trata de estudo “[...] 3. sistematizado, técnico, metodizado e com objetivo certo, princípio determinado, etc. [...]" (LUFT et al., 2000, p. 168). No Dicionário prático de Pedagogia, Queiroz (2003, p. 50) a define como "[...] conjunto de conhecimentos, atitudes e atividades racionais, socialmente adquiridos ou produzidos, estruturados com métodos, teorias e linguagens próprias [...]”. Houaiss e Villar (2001, p. 715) apresentam uma série de definições para o verbete "Ciência", dentre elas duas merecem destaque para o significado de Ciência discutido neste trabalho:

[...] 3 - corpo de conhecimentos sistematizados que, adquiridos via observação, identificação, pesquisa e explicação de determinadas categorias de fenômenos e fatos, questão formulados metódica e racionalmente [...]. 8 - [em]Fil. conhecimento que, em constante interrogação de seu método, suas origens e seus fins, procura obedecer a princípios válidos e rigorosos, almejando especialmente coerência interna e sistematicidade.

À luz das definições supramencionadas, a Ciência é constituída de objetos, métodos autônomos, técnicas próprias, princípios rígidos e sistemáticos que seguem uma lógica racional, experimental, sistematizada e com validação. Para Barros e Lehfeld (2000), a Ciência é composta pelas seguintes características: 1) racionalidade; 2) coerência; 3) representação do real; analítica; 4) investigativa; 5) metódica; 6) sistemática; 7) verificável; 8) agrupadora de objetos da mesma espécie para a investigação; 9) comunicável; e 10) mutável. 
Os métodos a serem empregados dependem do ramo da Ciência a ser pesquisado. Nesse sentido, os métodos se constituem de: dedutivo (proposto pelos racionalistas Descartes, Spinoza e Leibniz), indutivo (proposto pelos empiristas Bacon, Hobbes, Locke e Hume), dialético (proposto pelo filósofo do conhecimento absoluto, o alemão Hegel), hipotéticodedutivo (proposto pelo racionalista crítico Popper) e fenomenológico (proposto por Husserl) (GIL, 1999; LAKATOS; MARCONI, 2003; TRIVIÑOS, 1987).

Com efeito, os métodos são os caminhos a serem trilhados com intencionalidade e movimento no percurso da pesquisa. São conjuntos de procedimentos intelectuais e técnicos empregados na investigação. O método dedutivo, pertencente às Ciências Formais, “[...] onde a racionalização ou combinação de ideias - em sentido interpretativo - vale mais que a experimentação de caso por caso [...] é a marcha de uma visão orgânica para uma visão mecânica [...], o raciocínio que caminha do geral para o particular [...]” (MORAIS, 1988, p. 58-59, grifos do autor).

Quanto ao método indutivo, tende a fazer o caminho inverso do dedutivo. Partindo de uma experimentação particular concreta, chega-se a uma previsibilidade geral. "Mas não seja admitido o ponto de vista de que a indução obtém, necessariamente, conclusões gerais verdadeiras. Isto é ingênuo [...]” (MORAIS, 1988, p. 61). Esse método encontra enormes dificuldades no âmbito das Ciências Humanas, porque "[...] a previsibilidade nos seres humanos nunca é suficiente para que as ciências do homem avancem, em sua capacidade de previsão e controle, tão tranquilamente quanto as ciências empírico-formais [...]” (MORAIS, 1988, p. 63).

Com relação ao método dialético proposto por Hegel, consiste na arte do diálogo, da contraposição e da contradição de ideias, que, requerendo solução, leva a novas ideias. É um método de interpretação dinâmica e totalizante da realidade. Por esse método, os fatos não devem ser considerados fora do contexto social, político, econômico, etc. (GIL, 1999; LAKATOS; MARCONI, 2003).

O método hipotético-dedutivo acionado por Popper, diante das insuficiências de conhecimentos disponíveis para a explicação de determinado assunto, consiste no surgimento de um problema. Visando a explicar as dificuldades expressas no problema, são formuladas conjecturas ou hipóteses. “[...] Das hipóteses formuladas deduzem-se consequências que deverão ser testadas ou falseadas. Falsear significa tornar falsas as consequências deduzidas das hipóteses [...]" (GIL, 1999, p. 30).

Percebe-se que, se, por um lado, o método dedutivo procura de todas as formas confirmar a hipótese, por outro lado, o método hipotético-dedutivo busca insistentemente

\begin{tabular}{|c|c|c|c|c|}
\hline Govista Dialectus & Ano 10 & n. 23 & Maio - Agosto 2021 & p. 83 - 104 \\
\hline
\end{tabular}


evidências empíricas para invalidar essa ou essas hipóteses não somente na busca da negação, mas para encontrar uma validação segura.

Por seu turno, o método fenomenológico difundido por Husserl nem é dedutivo nem indutivo ou outro. Preocupa-se com a descrição direta do fenômeno tal qual como ele é. A realidade é construída socialmente a partir da compreensão interpretativa e comunicada. A realidade não é unilateral. Existem tantas quantas forem interpretadas pelos sujeitos/atores do processo de construção do conhecimento (GIL, 1999; TRIVIÑOS, 1987).

Ressalte-se que cada um desses métodos carrega consigo suas especificidades, que são exigidas de acordo com o objeto a ser investigado, visando à validação de suas respectivas pesquisas. Porém, por vezes, esses métodos são utilizados concomitantemente na pesquisa científica, dependendo da abordagem. Esses métodos também não garantem nenhuma forma pronta e acabada de conhecimento.

A ciência jamais persegue o objetivo ilusório de tornar finais ou mesmo prováveis
suas respostas. Ela avança, antes, rumo a um objetivo remoto e, não obstante,
atingível: o de sempre descobrir problemas novos, mais profundos e mais gerais, e de
sujeitar suas respostas, sempre provisórias, a testes sempre renovados e sempre
rigorosos. (POPPER, 1972, p. 308).

Assim, a produção da pesquisa científica deve aceitar como critérios científicos dos sistemas teóricos, segundo Popper (1972), a testabilidade, a refutabilidade e/ou a falsificabilidade. Com efeito, Popper (1972) fundamenta sua crítica ao método indutivo em “[...] favor da dedução analítica inconclusa, sob os auspícios da 'falsificabilidade' [...]", asseverando que "[...] dados sempre são incompletos, além de conterem pressupostos dedutivos implícitos [...]"” (DEMO, 2010, p. 72). "É preciso não nos esquecermos nunca de que a atividade científica é, em todos os seus aspectos, falível. Também é, em consequência, transformável” (MORAIS, 1988, p. 58).

Com efeito, o conhecimento científico, mesmo compromissado com a objetividade, não proporciona verdade pronta, última ou acabada, mas a aproximação do real, pois “[...] não temos o dom da onisciência, nem o poder de apreensão global instantânea do mundo, nossas aproximações científicas do real são sempre parciais [...]” (FARACO, 2005, p. 92). Porém, existem os que consideram a Ciência sob outros prismas, incluindo aí Ciência como expressiva da verdade.

Para o professor Martinho Rodrigues (2007, p. 170), Ciência é um modelo de discurso com “[...] diferentes significados. Há os que consideram (i) um discurso que expressa verdades, (ii) um discurso que se propõe a construir modelo útil, não necessariamente 
verdadeiro, ou apenas (iii) um discurso que se compromete com a validação". Cada um dos discursos supracitados está ancorado coerentemente em seus respectivos campos:

(i) A concepção de ciência como verdade é filha do realismo. Há um campo específico em que se pode efetivamente falar em ciência como verdade: é o território da descrição macroscópica, da verificação simples e direta, do que são exemplos a Anatomia e as aplicações da Geometria. (ii) A concepção de ciência como um trabalho voltado para a formulação de modelos úteis é adequada à pesquisa descritiva, quando voltada para objetos insusceptíveis de observação direta, como é o caso dos sucessivos modelos atômicos, de largo uso na Química. (iii) Existem objetos em relação aos quais não se exige a elaboração de modelos. Exige-se apenas um discurso comprometido com a validação. O processo de validação é o próprio núcleo da cientificidade. Consiste em submeter o discurso a um esforço para destruí-lo [...], abandoná-lo ou proceder à sua reforma, se ele não resistir ao dito falseamento [...]. (MARTINHO RODRIGUES, 2007, p. 170-171).

Definido num primeiro momento o que é Ciência, faz-se necessário perceber suas divisões, se é que as tem, e, caso as tenha, quais são essas divisões? Parece que uma das definições coerentes é a do professor Morais (1988, p. 58, grifos do autor), quando divide a Ciência em: Ciências Formais, Empírico-Formais e Hermenêuticas:

a) Ciências formais (matemática e lógica formal) - trabalham, repetimos, com elementos simbólicos de forma. b) Ciências empírico-formais (física, biologia, química etc.) - trabalham com dados empiricamente captados, com muito frequente mediação de instrumentos, mas que precisam ser racionalizados, principalmente com o auxílio das matemáticas. c) Ciências hermenêuticas (as ciências humanas), que visam a interpretação dos sinais que o homem inscreve no mundo à medida em que vive e se relaciona. Dedicam-se à interpretação científica do significado humano.

No caso das Ciências Formais (matemática e lógica formal), Morais (1988, p. 57) explica que, em razão de suas características "autoexplicativas e autossuficientes", são consideradas como atividades intelectuais não científicas por alguns teóricos contemporâneos. De todo modo, para a produção do conhecimento científico, são necessárias a escolha e a aplicação de método(s). Os métodos funcionam como degraus para se chegar ao alvo histórico pretendido. Desse modo, faz-se necessária sua escolha ou opção do(s) método(s): dedutivo, indutivo, dialético, hipotético-dedutivo e fenomenológico.

Debatido sobre o que é Ciência e suas nuances epistemológicas, partimos para a segunda parte da problemática sobre a História científica.

\section{A propósito de/da História}

A História da humanidade se dá numa dinâmica transformante e transformadora o tempo todo. Nesse sentido, a História e o seu fazer são processos contínuos. A discussão sobre

\begin{tabular}{|c|c|c|c|c|}
\hline Qovista Dialectus & Ano 10 & n. 23 & Maio - Agosto 2021 & p. 83 - 104 \\
\hline
\end{tabular}


o que é história, sua origem, sua teoria, objeto e método vem de longe. O debate mais fecundo, oriundo do nível acadêmico do ponto de vista epistemológico, centra-se na querela se História é ou não é Ciência ou que a História seja razoavelmente uma Ciência em construção ou Ciência da humanidade no tempo e no espaço. Mas, se, por um lado, a História, ao analisar fatos e coisas passadas, pode nos causar traumas e fazer emergir dolorosas lembranças/saudades, por outro, a “[...] vida tem necessidade do serviço da história" (NIETZSCHE, 2005, p. 82 apud SOUSA; CHAGAS, 2017, p. 233).

Com efeito, faz-se mister registrar que, até mesmo para aquele (Nietzsche), que desferiu intensas e profundas críticas do fazer científico moderno, inclusive aos excessos científicos da História, por ser utilizada pela ideologia alemã para uma pretensa cultura superior ou pseudocultura, a História não era questionada em seu pedestal como Ciência, no caso, a História Historiográfica, pois a não Historiográfica não se enquadra na História Científica. As críticas do filólogo se destinavam à Ciência, especificamente à eurocêntrica, de cunho positivista. Na visão crítica nietzschiana, a ciência moderna:

[...] observa todas as coisas cientificamente, e a única concepção verdadeira e aceitável para ela é a de que as coisas resultam do progresso, do desenvolvimento histórico, da lógica da continuidade histórica, e não de algo que se pressupõe, que já existe. Nesse sentido, a ciência vive em desacordo com as forças perpétuas e imperecíveis da arte e da religião, pois que essas necessitam da ilusão para se efetivarem. (SOUSA; CHAGAS, 2017, p. 243).

Quanto à Ciência Histórica, o irrequieto e intempestivo Nietzsche (2005 apud SOUSA; CHAGAS, 2017, p. 238) tecia suas críticas ao excesso, sobretudo ao método positivista aplicado às Ciências Humanas, especificamente à História:

Para Nietzsche, a profissionalização da história desencadeou dois problemas distintos, mas que estão interligados. O primeiro é que a história científica é um saber paralisador: não existe distinção entre fatos que importam e aqueles que não importam reter, todas as perspectivas apontam infinitamente para trás, para o que já foi, presente e passado são como que a mesma coisa [...]. O segundo é a formação de uma pseudocultura em oposição à verdadeira cultura alemã $[. .$.$] .$

Na realidade, o filólogo alemão parecia estar prevendo o que ocorreria mais de meio século depois, a partir de 1929, com o Movimento dos Annales ou Revolução Historiográfica dos Annales na França, mais tarde chamado de Escola dos Annales e/ou Nova História. Os Annales se contrapõem aos postulados positivistas baseados em métodos científicos rígidos nas Ciências Humanas, inclusive na História.

O Movimento dos Annales (1929) logo se tornaria uma revista de cunho acadêmicocientífico, tendo como fundadores os historiadores Marc Bloch e Lucien Febvre. Os Annales

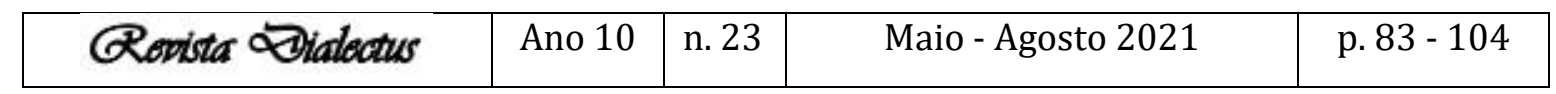


foram um movimento paradigmático de renovação teórico-metodológica do fazer e compreender a História, coordenado e organizado para romper decididamente com a histórianarrativa linear do legado historicista alemão, sobretudo rankeano, bem como com a noção de temporalidade, que encerrava os fatos em contextos puramente linear-cronológicos.

É racional destacar que, até meados das três primeiras décadas do século XX, a produção do conhecimento histórico era fundamentada na História Política dos grandes vultos e seus feitos, creditados exclusivamente em fontes escritas, sobretudo de documentos oficiais. Todavia, a partir do Movimento Historiográfico Francês dos Annales d'histoire économique et sociale, influenciado pela grande crise econômica de 1929, a História, como disciplina e como ciência, deixa de ser apenas História factual da política e de seus vultos para se tornar uma história-problema, de abordagem crítico-dialética, inter e transdisciplinar, consolidando seu método. A partir de então, a História amplia e inova suas abordagens, problemas e objetos de estudo, voltando-se para o cotidiano, a arte, os afazeres populares, as mentalidades, a psicologia social, a história das mulheres, dos escravos, enfim, volta-se para a história das mentalidades/vista de baixo. O Movimento dos Annales impulsiona, inclusive, a História Crítica e a Nova História Cultural.

Desse modo, a História crava sua ruptura com o maniqueísmo cientificista tradicional e factual positivista abrindo novos horizontes, estratégias e possibilidades interpretativas do saber e fazer humanos a partir de perspectivas historiográficas da História Vista de Baixo, fundamentada na Teoria da História das Mentalidades. Com efeito, o Movimento Historiográfico dos Annales possibilitou uma abertura imprescindível nos domínios da História, reatando seus vínculos e interdisciplinarizando suas abordagens com as demais Ciências Sociais, como Filosofia, Antropologia, Geografia, Psicologia, Economia, Sociologia, Psicanálise e demais derivações do conhecimento humano (BURKE, 1991).

Seguindo seu intento, o Movimento dos Annales adentra em sua segunda fase ou segunda geração a partir do pós-guerra, com a presença marcante de Fernand Braudel, que assume a direção da Revista em 1959. Braudel e sua equipe dos Annales contribui sistematicamente no aspecto da geo-história, com base em estudo da relação do homem e seu meio, bem como fomentou estudos considerando questões sobre o tempo histórico no âmbito de uma História de curta, média e longa duração. É a partir da segunda geração que o Movimento Historiográfico dos Annales começa a apresentar status de Escola, não no sentido físico, mas de segmento de ideias. Pari passu, despontam na segunda geração dos Annales campos da História Quantitativa ligados à História Econômica, à História Demográfica e a

\begin{tabular}{|c|c|c|c|c|}
\hline Qevista Dialectus & Ano 10 & n. 23 & Maio - Agosto 2021 & p. 83 - 104 \\
\hline
\end{tabular}


muitos outros domínios da História. Nesse período, consolida-se cada vez mais a ampliação de fontes, métodos e técnicas do fazer histórico-historiográfico, inclusive tendo a História Oral e as narrativas como recursos indispensáveis à produção de conhecimento histórico-científico (LE GOFF, 1976).

Prosseguindo na perspectiva da segunda geração dos Annales, seu principal representante, Braudel, meio que treina seus sucessores, como Jacques Le Goff, Le Roy Ladurie, Marc Ferro, Jaques Revel, Burguiére, etc., para a assunção da Revista como terceira geração, sobretudo a partir de 1970. Com efeito, a partir da terceira geração dos Annales, a História anuncia definitivamente a inexistência da totalidade do real. A ideia de uma História global e totalizante cai por terra. A História é fragmentada e decomposta. É a História serial ou História em retalhos. Doravante, os Annales passam a ser definitivamente conhecidos e identificados como a Nouvelle Historie (Nova História). A partir desse momento, aumentou a pluralidade de ideias e a inclusão de mulheres e seus papéis na História. Essa fase se apresenta mais aberta, aceitando ideias além da França e da Europa, retomando inclusive a História Narrativa, como as biografias científicas e eventos políticos de forma problematizada (BURKE, 1991).

Outra característica notória da terceira geração dos Annales ou Nova História foi a chamada viragem antropológica, que incorpora significativamente muitos conceitos, técnicas e abordagens da antropologia cultural e/ou simbólica. Com isso, a História passa a pluralizar mais ainda seus objetos de estudo com base na micro história, incluindo temáticas como a História do Cotidiano, História Regional, História Vista de Baixo, História dos Marginalizados, História dos Vencidos, enfim, História dos pequenos grupos e periféricos, e não apenas História da sociedade e central.

Nessa etapa, também os Annales retomaram o que tanto outrora criticaram: a História Narrativa e as abordagens literárias. Há um deslocamento da busca cientificista do objeto real. Em vez do conhecimento do real, o mais importante é a criação e/ou invenção do historiador. O valor do trabalho do historiador não está tanto no conteúdo, mas na estética da inventividade. Neste caso, é posta também em xeque a cientificidade aos moldes rígidos do legado cientificista novamente. Nesse sentido, a História é revista como atividade divertida e prazerosa para si e para os outros. A História não pode ser nem querer para si os postulados rígidos da objetividade com o mesmo fim das Ciências Empírico-Formais e Formais. A História é e deve ser feita levando em conta as subjetividades, sonhos e imaginários, realidades e simbolismos (XAVIER et al., 2018).

\begin{tabular}{|c|c|c|c|c|}
\hline Q Rovista Dialectus & Ano 10 & n. 23 & Maio - Agosto 2021 & p. $83-104$ \\
\hline
\end{tabular}




\section{É criterioso deixar posto que a Escola dos Annales é frequentemente} contextualizada entre 1929 a 1989. Contudo, há uma discussão sobre a existência de uma quarta geração a partir de 1989. A característica principal dessa possível quarta geração dos Annales seria o significativo desenvolvimento da História Cultural. Porém, para alguns historiadores, o que é chamada de quarta geração dos Annales configura-se apenas como uma reação contra Braudel e/ou contra qualquer determinismo.

Em âmbito mais geral, a análise gira em torno de que a disciplina História, durante muito tempo, foi ministrada de forma fria e tecnicista, visto que a História Tradicional tinha por meta contar o passado, sem questionar as implicações num tempo presente para o tempo futuro. Desse modo, torna-se, assim, enfadonha e tediosa em sua aprendizagem, haja vista o parâmetro de ensino-aprendizagem que a norteava, encerrando-se num paradigma de aprendizagem que não gera nem possibilita uma discussão que promova uma compreensão dos meandros que desencadeiam os fenômenos que enxertam as relações sócio humanas.

A palavra história é uma palavra antiquíssima: [tão antiga que às vezes nos cansamos dela. Raramente, é verdade, chegou-se a querer riscá-la completamente do vocabulário]. Os próprios sociólogos da era durkheimiana lhe dão espaço. Mas é para relegá-la a um singelo cantinho das ciências do homem: espécie de calabouço onde, reservando à sociologia tudo que lhes parece suscetível de análise racional, despejam os fatos humanos julgados ao mesmo tempo mais superficiais e mais fortuitos. Vamos preservarlhes aqui, ao contrário, sua significação mais ampla. [O que não proíbe, antecipadamente, nenhuma orientação de pesquisa, deva ela voltar-se de preferência para o indivíduo ou para a sociedade, para a descrição das crises momentâneas ou a busca dos elementos mais duradouros; o que também não encerra em si mesmo nenhum credo; não diz respeito, segundo sua etimologia primordial, sendo à pesquisa]. Seguramente, desde que surgiu, já há mais de dois milênios, nos lábios dos homens, ela mudou muito de conteúdo. É a sorte, na linguagem, de todos os termos verdadeiramente vivos. Se as ciências tivessem, a cada uma de suas conquistas, que buscar por uma nova denominação para elas, que batismos e que perdas de tempo no reino das academias! Mesmo permanecendo pacificamente fiel a seu glorioso nome helênico, nossa história não será absolutamente, por isso, aquela que escrevia Hecateu de Mileto; assim como a física de lorde Kelvin ou de Langevin não é a de Aristóteles. (BLOCH, 2001, p. 51).

Outra particularidade do termo "História", e aí talvez resida a essência de sua polissemia e ambiguidade, é o fato de que:

[...] é a única disciplina ou campo de saber que traz como sua própria designação um nome que coincide diretamente com seu objeto de estudo. História [...] é, de um lado, o discurso e o tipo de conhecimento que um historiador elabora; mas é assim, enquanto a Geografia estuda a Terra, e a Física estuda os diversos fenômenos físicos, e a Crítica Literária estuda a Literatura, a História dedica-se a estudar a própria história. Não raro esta coincidência entre o nome de uma disciplina e a designação de seu próprio objeto de estudos produz ambiguidades, razão pela qual frequentemente a História - enquanto campo de conhecimento ou prática disciplinar - costuma ser referida também como 'Historiografia'. De outra parte, esta é certamente uma das mais fascinantes ambiguidades da história do conhecimento científico. Para parodiar um verso da bela canção Terra, de Caetano Veloso, podemos dizer que a História é a

\begin{tabular}{|c|c|c|c|c|}
\hline Rovista Dialectus & Ano 10 & n. 23 & Maio - Agosto 2021 & p. $83-104$ \\
\hline
\end{tabular}


única disciplina que carrega, através de sua viagem errante pelo vasto universo do conhecimento, 'o nome de sua própria carne'. (BARROS, 2011, p. 30).

Na busca incessante de desvelar com maior nitidez e compreensão possíveis o significado da palavra "História", caminhamos descortinando outros horizontes. Etimologicamente, o termo "História" é oriundo do grego antigo "íüxopía" e do latim "Historía":

\begin{abstract}
Esse termo, que em geral significa pesquisa, informação ou narração e que já em grego era usado para indicar a resenha ou a narração dos fatos humanos, apresenta hoje uma ambiguidade fundamental: significa, por um lado, o conhecimento de tais fatos ou a ciência que disciplina e dirige esse conhecimento (historia rerum gestarum) e, por outro, os próprios fatos ou a totalidade deles (resgestaé). Essa ambiguidade está presente em todas as atuais línguas cultas. (ABBAGNANO, 1998, p. 502).
\end{abstract}

Certamente, em razão de sua polissemia, a História ou o conhecimento histórico, ao procura investigar os fatos, objeto de estudo da Ciência da História, entra na seara pluralista de outras várias produções do conhecimento. Abre-se aí um leque de possibilidades de saberes, sobretudo quando nos debruçamos na tentativa de compreender o significado da totalidade desses fatos. Desse modo, o conhecimento histórico apresenta-se como algo instigante, dinâmico e infindável, exigindo continuamente um exercício hermenêutico constante. Nesse sentido, necessário é ter uma compreensão do que estamos falando, ou seja: o que é História? Entre tantas concepções já citadas e ainda por vir, o historiador Barros (2011) resume o termo "História" como sendo: 1) estudo sobre a realidade humana no Tempo; 2) forma de conhecimento produzida pela figura subjetiva do historiador profissional, este mesmo inserido em uma comunidade de historiadores; 3) investigação sistemática e racionalidade conduzida; 4) uso de método apoiado nas fontes históricas; 5) exposição (problematizada ou não) em forma de relato e de análise; e 6) intenção de produzir um conhecimento verdadeiro.

Fazemos uma ressalva com relação à origem da História no mundo ocidental, pois não está no nosso plano levar em consideração a narrativa bíblica do Éden, onde estaria o princípio de tudo, inclusive o da História. Não empreendemos tal narrativa por fatores óbvios, descritos a seguir. Raciocinando sobre esse assunto, Hegel (2001) comenta que muitos povos, incluindo escritores, aceitaram e aceitam a ideia de que a origem da História do mundo está ancorada pioneiramente na narrativa bíblica ou em descobertas consideradas científicas, como a da astronomia, atribuída aos hindus. Hegel (2001, p. 109) assevera ainda que:

A investigação filosófica pode e deve começar o estudo da história apenas onde a Razão começa a manifestar sua existência no mundo, onde aparecem a consciência, a vontade e a ação e não onde tudo isso ainda é uma potencialidade irrealizada. A existência inorgânica do Espírito, a capacidade ainda inconsciente - ou, se preferem, a excelência - da liberdade, do bem e do mal e, assim, das leis não é o objeto da história. A moral natural e ao mesmo tempo religiosa é a lealdade da família. Nesta sociedade a moral

\begin{tabular}{|c|c|c|c|c|}
\hline Q Rovista Dialeatus & Ano 10 & n. 23 & Maio - Agosto 2021 & p. 83 - 104 \\
\hline
\end{tabular}


consiste no próprio fato de que seus membros se comportem uns para com os outros não por livre-arbítrio como indivíduos, não como pessoas. É por essa mesma razão que a família continua excluída do desenvolvimento em que a história teve sua origem (ela é pré-histórica). Somente quando a unidade espiritual passa além deste círculo de sentimento e amor natural, chegando à consciência da personalidade, é que surge o núcleo sombrio e rigoroso em que nem a natureza nem o espírito são abertos e transparentes e onde ambos podem tornar-se abertos e transparentes apenas através de mais trabalho daquela vontade consciente e através do demorado processo cultural.

É valioso refletir como pensamos, escrevemos e/ou ensinamos acerca do conhecimento histórico: se de forma reflexivo-crítica, reprodutora-tradicional, cronológicolinear, mística ou religiosa. Outra consideração a ser pautada é com referência aos métodos e fontes do/para o conhecimento histórico.

Na utilização de métodos e suas respectivas fontes, o historiador estabelece meta, critério e objetividade no âmbito do conhecimento e da produção histórica. Assim, a formulação das hipóteses, a delimitação do objeto, objetivos, justificativas, problemáticas, trilhas metodológicas e a fundamentação teórica, fontes empíricas e de pesquisa de campo, através do recurso da História Oral, são mais bem vislumbradas e escolhidas pelo produtor de material histórico, bem como o que ensinar na disciplina de História. Esta é uma querela que vem ressoando desde há muito tempo. Aliás, como já bem disse Braudel (2002, p. 389), o debate sobre o ensino de História:

É uma velha querela que sempre faz sucesso e não deixa ninguém indiferente, nem o público, mais do que nunca apaixonado pela história, nem os políticos, obrigados a ficar à espreita, nem os jornalistas e muito menos os professores de história. É uma velha querela que não nos ensina nada de novo e cujo círculo, entretanto, não para de crescer. Todas as controvérsias nela encontram facilmente abrigo. Aí chegam ao troar do canhão, como as boas tropas [...]. Enfim, é questionada a evolução da própria história, em suas formas diversas. Para uns, a história tradicional, fiel à narrativa, escrava da narrativa, atulha as memórias, prodigalizando, sem a menor preocupação de poupá-las, as datas, os nomes dos heróis, os fatos e gestos das grandes personagens; para outros, a história 'nova', que se quer 'científica', que cultiva entre outras coisas a longa duração e negligencia o acontecimento, seria responsável por esses malogros didáticos que constituem verdadeiras catástrofes, acarretando quando menos o esquecimento imperdoável da cronologia. Essa querela dos Antigos e Modernos não é acaso um simples pretexto? Num debate que é da pedagogia e não da teoria científica, ela ocupa os problemas e as 'culpabilidades', em vez de esclarecê-los.

Vale ressaltar que a História referendada trata, sobretudo, da História Escolar e/ou da Cotidiana (formadora da memória coletiva), sobressaindo-se, assim, a História Acadêmica, haja vista ser:

[...] possível propor a existência de três representações do passado, situadas de modo muito distinto na experiência social do indivíduo e das instituições. Por um lado, o registro da história que aparece na escola; por outro lado, o da história cotidiana, como elemento de memória coletiva que, de uma forma ou de outra, inscreve-se permanentemente, experiência e formação mediante, na mente e nos corpos dos

\begin{tabular}{|c|c|c|c|c|}
\hline Q & Ano 10 & n. 23 & Maio - Agosto 2021 & p. 83 - 104 \\
\hline
\end{tabular}


membros de cada sociedade, e articula relatos compartilhados em torno da identidade, dos sistemas de valores e das crenças comuns. Por último, existe a história acadêmica ou historiográfica, prezada pelos historiadores e pesquisadores sociais, conforme a lógica disciplinar de um saber instituído sob condições sociais e institucionais específicas. (CARRETERO, 2010, p. 33).

Posto isso, percebem-se de imediato algumas problemáticas a serem consideradas a partir das assertivas supracitadas, a saber: História é Ciência? Para que serve seu estudo? Como se diferenciam e se relacionam esses três campos de saberes: História, Historiografia e Ciência? Essas são questões cruciais a serem consideradas no campo do debate envolvendo a História.

\begin{abstract}
A senda a ser trilhada pelo historiador pode conduzir a deusa Clio, por sua vez, a um autoexame, uma história da História: seria ela uma crônica dos acontecimentos, mas também - e talvez, principalmente - de espécies de fenômenos compreendidos como temas? Caso a escolha recaia sobre a História como ciência, abre-se a discussão sobre o que seja isso [...]. A história científica pode ser entendida pelo viés do empirismo ou do racionalismo, podendo, em ambas as hipóteses, ser considerada uma narrativa inteira, que a tudo articula; ou um estudo de objetos específicos, sem a pretensão de alcançar uma totalidade articulada, que possa ser expressa por uma grande narrativa [...]. Todos os caminhos conduzem a numerosos problemas teóricos, cada um dos quais enseja a produção de uma história distinta, com significados diversos para os fatos, personagens, fenômenos e ambientes. A vertente do cientificismo histórico, prenhe de objetivismo, inferências e generalizações, faculta ao historiador seguir a trilha da ciência monista ou o caminho do chamado dualismo metodológico. Pela primeira, os métodos praticados pelas ciências da natureza seriam os mesmos das chamadas ciências humanas ou histórico-sociais. O último propugna por métodos distintos para objetos diferentes. (MARTINHO RODRIGUES, 2009, p. 422-423).
\end{abstract}

Com efeito, é imperioso lembrar que a produção de uma História cunhada de científica pautou-se por muito tempo, sobretudo no século XIX, apenas por fontes oficiais escritas, esquecendo que o princípio de toda produção do conhecimento histórico no Ocidente teve como base as narrativas, crônicas, literaturas e contos populares, a partir do século $\mathrm{V}$, na Grécia. Desse modo, a discussão sobre a etimologia da palavra "História” carece de revisitamento.

\title{
A periodização do tempo histórico
}

A periodização do tempo histórico no Ocidente convencionou-se em: Pré-História - do surgimento do homem na Terra ao aparecimento da escrita, cerca de 4000 a 3500 anos antes de Cristo (a.C.) - e História. A Pré-História, que compreende as sociedades primitivas, é subdividida em três períodos: Paleolítico ou Período da Pedra Lascada; Neolítico ou Período da Pedra Polida; e Idade dos Metais. Os termos "selvageria", "barbárie” e "civilização" são atribuídos, respectivamente, a cada um dos períodos mencionados (MOTA; BRAICK, 1997).

\begin{tabular}{|l|l|l|l|l|}
\hline Qevista Dialectus & Ano 10 & n. 23 & Maio - Agosto 2021 & p. 83 - 104 \\
\hline
\end{tabular}


Atualmente o termo "Pré-História" é bastante discutido, pois o ser humano, a partir do momento em que surge na Terra, passa a transformar a natureza em busca de sua própria sobrevivência e, assim, já faz a sua história. Com efeito, o referido vocábulo é preconceituoso no sentido mais geral, pois serve para definir e conceituar que a humanidade somente faz parte do processo histórico a partir do surgimento da escrita. Desse modo, seria menos pejorativo o uso do termo "Pré-Escrita", e não "Pré-História", até mesmo porque o tempo histórico não necessariamente corresponde ao tempo cronológico. Por exemplo, “[...] A sociedade txucarramãe apresenta características do paleolítico, embora viva no Brasil na era da globalização" (MOTA; BRAICK, 1997, p. 2).

Por sua vez, a periodização da História com significativa aceitação de influência eurocêntrica, indicando que a História é uma totalidade, de início, meio e fim, é a divisão em: História Antiga (do surgimento da escrita à queda do Império Romano no Ocidente em fins do século V); Idade Medieval (do século V ao XV); Idade Moderna (do século XVI ao fim do século XVIII); e Idade Contemporânea (iniciada em fins do século XVIII e estendida aos dias atuais). Ressalte-se que a cada marco desse tomado há todo um processo de transição, dado que não pode haver uma partitura desconexa no tempo histórico, sob pena de se matar a própria História. Além disso, consoante o pensamento de Martinho Rodrigues (2008, p. 452), “[...] I. Períodos não são dados naturais, mas elaboração do pesquisador [...]. II. A construção dos períodos históricos é fortemente influenciada pelas referências teórico-metodológicas do pesquisador que a cria”.

Para não se cair em discurso redundante, resume-se que os dicionários anteriormente consultados definem História como "ciência que estuda o passado". Essa definição, além de simplista, parece estar eivada de preconceitos ou no mínimo de desconhecimento sobre o que seja História e seu significado nos dias atuais. Hobsbawm (1998, p. 35) pontua que "[...] A história, unidade de passado, presente e futuro, pode ser algo universalmente apreendido, por deficiente que seja a capacidade humana de evocá-la e registrá-la [...]”.

Com efeito, a História, no âmbito de uma ciência hermenêutica, pode ser considerada a ciência que procura compreender e explicitar a produção da cultura humana no decorrer do tempo e no espaço. Para tanto, a História dispõe de objeto (o fato histórico), objetivo (a transformação social), de método (fontes, linguagens, etc.) e de inúmeras teorias. Teorias no sentido de "visão de mundo", podendo ser discutida essa visão em três níveis: teoria como "[...] um campo de estudos, um modo de apreender o mundo e teoria no sentido de modelos ou sistemas explicativos criados para compreender um determinado fenômeno, aspecto da realidade ou objeto de estudos" (BARROS, 2011, p. 43).

\begin{tabular}{|l|l|l|l|l|}
\hline Q & Anista 10 & n. 23 & Maio - Agosto 2021 & p. 83 - 104 \\
\hline
\end{tabular}


A 'Teoria', enfim, se [sic] desenrola a partir de um padrão discursivo, argumentativo, no qual vamos a cada novo momento encaixando uma coisa na outra ou interconectando pensamentos, ao mesmo tempo em que buscamos demonstrar esses pensamentos passo a passo - seja a partir da comprovação de informações através de materiais e impressões que temos à disposição, seja a partir de inferências que podemos estabelecer a partir desses mesmos materiais ou de consequências dos próprios pensamentos que formulamos antes. (BARROS, 2011, p. 53).

Dispondo desses mecanismos, cabe ao historiador interpretar os acontecimentos históricos descendo dos grilhões rígidos dos métodos preestabelecidos para beber nas águas mais profundas da subjetividade humana. A História, tal qual é concebida atualmente, atravessou um longo processo de transformação e sucessivas "[...] rupturas com o gênero literário, em torno da busca da verdade [...]” (DOSSE, 2003, p. 13). Essas rupturas iniciam por volta do século V a.C. na Grécia, quando surge o novo personagem da História, o histor, na figura de Heródoto, que tem por missão principal “[...] retardar o desaparecimento dos traços da atividade dos homens [...]” (DOSSE, 2003, p. 13).

Até a Grécia do século V a.C., a História se processava com os grandes feitos e fatos de grandes personagens, que se tornavam heróis na concepção das narrativas contadas sem preocupação alguma com as causas, com os resultados ou com a própria veracidade, sem nenhum tipo de recurso metodológico. A História, a partir de Heródoto de Halicarnasso, surge como um gênero novo, cujo recurso é o trabalho de investigação apurado no âmago das fontes. A História narrativa, pertencente “[...] ao reino do aedo, do poeta contador de lendas e dispensador do Kleos (a glória imortal para o herói) [...]” (DOSSE, 2003, p. 13) é substituída pelo trabalho de investigação (historiê) do histor.

Em seguida, a História adentra no reino do pragmatismo, com os gregos Heródoto e Tucídides e os romanos Cícero e Políbio, com o objetivo de ser utilitária e justa. Esse tipo de História é basilado em torno de "[...] três imperativos: explicar, expondo as causas e os efeitos dos acontecimentos; julgar, considerando a justiça e a oportunidade das decisões e dos atos dos homens; advertir, mesclando o relato histórico com preceitos [...]" (DOSSE, 2003, p. 49). A História pragmática ao certo ganha inteligibilidade, porém, em razão do uso de sistema de provas hierarquizado, “[...] perde em emoção e o método apodíctico subordina tudo à demonstração [...]" (DOSSE, 2003, p. 49). Caracteriza-se pela preocupação didática, busca mudar os costumes passados, tenta corrigir os contemporâneos expondo o passado como mero exemplo.

O historiador é portador de um crivo de inteligibilidade abstrata que lhe permite ler o caos do real. Um acontecimento histórico recebe, segundo Políbio, uma explicação completa apenas no centro da interferência de três pontos de vista: a determinação de sua data, a modalidade de seu desenrolar e a causa de sua irrupção. Para conseguir tal

\begin{tabular}{|l|l|l|l|c|}
\hline Rovista Dialectus & Ano 10 & n. 23 & Maio - Agosto 2021 & p. 83 - 104 \\
\hline
\end{tabular}


explicação, o historiador deve dominar um método que Políbio qualifica de apodítico, o que significa demonstrativo em torno de um sistema de provas. Essa história apodíctica necessita de uma demonstração contínua que se empenha em provar que a versão dos fatos relatados é a mais autêntica, acompanhando-a de provas, múltiplos testemunhos. (DOSSE, 2003, p. 49).

Em 1880, na cidade de Paris, o historiador galga o status de profissional científico, diferenciando-se dos literatas e construindo para si um modelo próprio para poder pertencer a uma “[...] comunidade de sábios no seio da qual sua subjetividade é mantida à parte. O bom historiador é reconhecível por seu amor ao trabalho, sua modéstia e critérios incontestáveis de seu julgamento científico [...]" (DOSSE, 2003, p. 37-38).

Com a proclamação do império da razão e a sacralização cientificista, ideário herdado do Iluminismo, a História no século XIX ganha o status de ciência e, para tanto, terá de se submeter a um enxágue profundo de fontes, métodos, técnicas e abordagens. Desse modo, os relatos orais e as memórias, construídas a partir de subjetividades, são postos em suspeição como fontes seguras para o fazer histórico. É o caso proposto por Fustel de Coulanges em artigo publicado na Revista das Questões Históricas de 1887, no qual expressa sua idolatria às fontes escritas e documentais, repudiando toda e qualquer contribuição subjetiva ou hipóteses. “[...] Fustel restringe, portanto, a prática histórica a um cientificismo reativo, a um empenho crispado sobre os textos, à recusa de toda forma literária da escritura histórica e à anulação do historiador [...]" (DOSSE, 2003, p. 46).

No século XIX, considerado o século da História, existe toda uma preocupação em se alcançar a verdade histórica, com método a ser trilhado, com as causas e consequências, tempos e espaços. Os historiadores, sobretudo na França, criam a escola “[...] 'metódica' colocam-se como cientistas puros e duros e anunciam uma ruptura radical com a literatura [...]", (DOSSE, 2003, p. 37). A “[...] História: [...] a partir do século XIX, tornou-se científica, e com esse mesmo espírito seguiu pelo século XX adentro [...]” (BARROS, 2011, p. 57).

A História no século XIX também será recheada de algumas concepções teóricometodológicas com aspectos paradigmáticos historiográficos, tentando compreender e explicar o sentido das coisas, como: o Positivismo, de Augusto Comte, para quem o progresso histórico da humanidade dependia de leis e hierarquização das Ciências; e a concepção Providencialista ou Teológica, segundo a qual todo acontecimento é determinação de Deus, fundamentada na interpretação das obras A cidade de Deus, de Agostinho; Discurso sobre a História Universal, de Jacques Bossuet; e História Universal, de Césare Cantu (BARROS, 2011).

$\mathrm{Na}$ concepção historicista universalizante, fundamentada na obra $A$ razão na História - uma introdução geral à Filosofia da História, de Hegel (2008, p. 18 apud BARROS, 
2011, p. 124), a História segue uma “[...] marcha racional e necessária do espírito universal [...]”. Em contraposição à concepção de História Idealista hegeliana, surge a concepção materialista da História, cujas pilastras são lançadas por Marx e Engels com a publicação do panfleto o Manifesto Comunista de 1848, culminando com a obra máxima de Marx, O capital. Os autores deixam explícito que as transformações ocorridas e por ocorrer na História são de ordem determinantemente econômica e pelas condições de vida material. Com efeito, buscam “[...] entender a história simultaneamente sob a perspectiva da 'luta de classes' e da sucessão dialética de modos de produção [...]”" (BARROS, 2011, p. 127).

Outra concepção surgida no século XIX, a Psicológico-Social, fundamenta-se na obra de Wilhem Wundt Elementos de psicologia das multidões, segundo a qual os fatos históricos são produtos do estado psicológico de uma determinada coletividade ou agrupamento social. Essas e tantas outras abordagens teórico-metodológicas podem ser arguidas em relação à compreensão de mundo, dependendo do aporte teórico na produção histórica.

Essas abordagens teóricas se consolidam com os estudos historicistas de Leopoldo von Ranke, para quem a História só é cognoscível na medida em que as singularidades são investigadas e interpretadas, haja vista que o todo da História jamais será de alcance da visão humana. Ranke acreditava que a História é o desenvolvimento do espírito no tempo, o progresso da razão e uma arte que sempre necessitará da habilidade humana para interpretá-la, dando vez e voz aos acontecimentos passados (HOLANDA, 1979; RIBEIRO, 2005).

\footnotetext{
A história científica pode ser entendida pelo viés do empirismo ou do racionalismo, podendo, em ambas as hipóteses, ser considerada uma narrativa inteira, que a tudo articula; ou um estudo de objetos específicos, sem a pretensão de alcançar uma totalidade articulada, que possa ser expressa por uma grande narrativa. Todos os caminhos conduzem a numerosos problemas teóricos, cada um dos quais enseja a produção de uma história distinta, com significados diversos para os fatos, personagens, fenômenos e ambientes. (MARTINHO RODRIGUES, 2009, p. 422-423).
}

O trabalho do historiador, seja ensejado pela prática, seja ensejado pela teoria, pauta-se indispensavelmente pela interpretação e compreensão das realidades contextuais, a partir dos fatos históricos, no âmbito de uma dinâmica historiográfica atemporal. Para tanto, o conhecimento histórico depende de um processo analítico e hermenêutico construtivo e reconstrutivo a partir das fontes, daí que o “[...] historiador é necessariamente um selecionador” (CARR, 1987, p. 15).

Todavia, como o fato não fala por si só, dependendo do olhar do sujeito (historiê), dos paradigmas e dos contextos, o seu desvelamento ou estudo possibilita "Histórias no plural", e não uma História singularizada. Desse modo, trabalhar com o fato histórico não se limita

\begin{tabular}{|l|l|l|l|l|}
\hline Q & Ano 10 & n. 23 & Maio - Agosto 2021 & p. 83 - 104 \\
\hline
\end{tabular}


saber o que, como, onde e quando, é mais importante refletir e raciocinar sobre o porquê ou os porquês. Nisso reside uma das lúcidas diferenças da História em relação ao modelo metódico enrijecido das Ciências Formais e Empírico-Formais. Como assegura Dosse (2003, p. 50), o trabalho do historiador em buscar as causas dos fatos é uma resultante de "[...] operações mentais que precedem a ação numa concepção intelectualista e psicologizante [...]. Ao contrário dos fenômenos naturais, as causas advêm de uma imaginação criadora, da razão e de uma vontade estreitamente subordinada ao entendimento".

\section{Considerações finais}

A propósito de considerações finais desta escrita, e não das querelas que envolvem a temática, é possível tecermos alguns juízos de valor levando em conta a principal problemática e objetivo elencados no início deste texto, quais sejam: se a História é Ciência e como é possível explicitar os argumentos epistemológicos no tocante ao ensino-aprendizagem de História como uma Ciência Humana que trata dos feitos e fatos ativos e passivos do homem (ser humano) no tempo e espaço no mundo.

Com efeito, antes de se firmar alguma posição de se a História é Ciência ou não, faz-se necessário dizer o que é Ciência. Pelo que apuramos e constatamos no bojo desta escrita, Ciência é a busca de uma verdade não absoluta a partir de uma produção de um conhecimento sistematizado e interpretado à luz de fontes. Esse conhecimento, ao ser científico, pode ser produzido a partir do empírico e/ou racional, sendo verificável, revisionável, mutável e refutável. Para o histor, esse conhecimento centra-se na hermenêutica diante dos fatos históricos apresentados pelas fontes.

Consideramos ser valioso refletir a respeito de como pensamos, escrevemos e/ou ensinamos acerca do conhecimento histórico, se de uma forma reflexivo-crítica, reprodutoratradicional, cronológico-linear, mística ou religiosa. Outra consideração a ser pautada é com referência ao método do conhecimento histórico quanto ao seu uso e identificação. Com efeito, é imperioso lembrar que a produção de uma História cunhada de científica pautou-se por muito tempo, sobretudo no século XIX, apenas por fontes oficiais escritas, esquecendo que o princípio de toda produção do conhecimento histórico no Ocidente teve como base as narrativas, crônicas, literaturas e contos populares, a partir do século V, sobretudo na Grécia.

Não há um modelo pronto e acabado na busca do conhecimento histórico, muito embora saibamos que também não exista uma produção cristalina com neutralidade. Desse

\begin{tabular}{|l|l|l|l|l|}
\hline Govista Dialectus & Ano 10 & n. 23 & Maio - Agosto 2021 & p. 83 - 104 \\
\hline
\end{tabular}


modo, as fontes fornecedoras para as pesquisas históricas nas mais diversas searas do conhecimento são constituídas por uma gama de material diverso, eclético e sem hierarquia de credibilidade concernente à linguagem escrita ou falada.

A História é Ciência de Raciocínio e essencialmente investigativa que busca o conhecimento das ações ou omissões dos viventes no tempo e no espaço, seus efeitos, impactos ou sentidos nos diferentes contextos da sociedade. A História, para sua sobrevivência mais saudável e holística, é alimentada pela memória num processo de interdependência dos imbatíveis guardiões e guardiãs do tempo, que, através de suas vozes e ecos escritos ou narrados, expõe os desejos, prazeres e/ou dores de um tempo volátil e obstinado ao advento do sempre novo, indefinida e infinitamente.

Nessa esteira, do ponto de vista dos critérios adotados pelas diretrizes determinantes cientificistas, principalmente em relação às Ciências Empírico-Formais e Formais, podemos responder afirmativamente que a História é, sim, Ciência, por possuir método, objeto de investigação, objetivo social, fontes, critérios, técnicas e sistematização teórico-metodológica e epistemológica. Por outro lado, também faz necessário afirmarmos que a História, como produção de conhecimento e Ciência Hermenêutica, não se satisfaz apenas com os postulados rígidos, frios e objetivistas determinados pelo cartesianismo ou pelo baconianismo, ou até mesmo pelo popperianismo. A História vai mais além, é alegre e se delicia com o subjetivismo dos sujeitos de todas as classes sociais e da pluralidade de fontes. Eis aí onde reside a grande contribuição da Escola dos Annales, principalmente a partir da Nova História, que possibilitou ouvir as vozes, dores e clamores dos sujeitos sufocados, abafados, obstruídos e oprimidos pelos discursos dos dominantes da História Tradicional.

A História pode ser considerada uma Ciência porque é produzida a partir de um corpo de conhecimentos sistematizado e interpretado à luz de fontes selecionadas pelo histor, que conduz a um trabalho verificável, revisionável, transformável e refutável. Estas são as características comuns ao status da Ciência. Essa compreensão centra-se na hermenêutica do historiador diante do fato histórico contextualizado, filosofado e historiografado. Assim se produz a História Científica.

Por fim, a História Acadêmico-Científica exige indispensavelmente investigação renovada sobre os fatos históricos a partir das fontes dentro de um processo analítico e dialético do presente ao passado, e vice-versa, projetando-se para o futuro. Assim, a História e o historiador buscam compreender interdisciplinarmente as várias searas da vida humana, como

\begin{tabular}{|l|l|l|l|l|}
\hline Qevista Dialectus & Ano 10 & n. 23 & Maio - Agosto 2021 & p. 83 - 104 \\
\hline
\end{tabular}


a econômica, a política, a social e a cultural, visando a alcançar uma verdade não absoluta, mas epistemologicamente validável e confiável, embora refutável.

\section{REFERÊNCIAS}

ABBAGNANO, Nicola. Dicionário de Filosofia. São Paulo: Martins Fontes, 1998.

BACHELARD, Gaston. A intuição do instante. Campinas: Verus, 2007.

BACON, Francis. Novum Organum ou verdadeiras indicações acerca da interpretação da natureza: Nova Atlântida. São Paulo: Nova Cultural, 1997.

BARROS, Aidil Jesus Paes de; LEHFELD, Neide Aparecida de Souza. Fundamentos de metodologia. São Paulo: Makron, 2000.

BARROS, José D’Assunção. Teoria da História. Petrópolis: Vozes, 2011.

BLOCH, March. Apologia da História ou O ofício do historiador. Rio de Janeiro: Jorge Zahar, 2001.

BRAUDEL, Fernand. Reflexões sobre a História. 2. ed. São Paulo: Martins Fontes, 2002.

BURKE, Peter. A Escola dos Annales: 1929-1989. São Paulo: Unesp, 1991.

CARR, Edward Hallett. Que é história?. 5. ed. São Paulo: Paz e Terra, 1987.

CARRETERO, Mario. Documentos de identidade: a construção da memória histórica em um mundo globalizado. Porto Alegre: Artmed, 2010.

DEMO, Pedro. Saber pensar é questionar. Brasília, DF: Liber, 2010.

DOSSE, François. A História. Bauru: Edusc, 2003.

FARACO, Carlos Alberto. Linguística histórica: uma introdução ao estudo da história das línguas. São Paulo: Parábola, 2005.

GIL, Antonio Carlos. Métodos e técnicas de pesquisa social. São Paulo: Atlas, 1999.

HEGEL, Georg Wilhelm Friedrich. A razão na História: uma introdução geral à Filosofia da História. 2. ed. São Paulo: Centauro, 2001.

HOBSBAWM, Eric J. Sobre história. São Paulo: Companhia das Letras, 1998.

HOLANDA, Sérgio Buarque de (Org.). Leopold Von Ranke: História. São Paulo: Ática, 1979.

HOUAISS, Antônio; VILLAR, Mauro de Salles. Dicionário Houaiss da língua portuguesa. Rio de Janeiro: Objetiva, 2001.

\begin{tabular}{|l|l|l|l|l|}
\hline Qevista Dialectus & Ano 10 & n. 23 & Maio - Agosto 2021 & p. 83 - 104 \\
\hline
\end{tabular}


LAKATOS, Eva Maria; MARCONI, Marina de Andrade. Fundamentos de metodologia científica. 5. ed. São Paulo: Atlas, 2003.

LE GOFF, Jacques. História: novos objetos. Rio de Janeiro: Francisco Alves, 1976.

LUFT, Celso Pedro et al. Minidicionário Luft. São Paulo: Ática, 2000.

MARTINHO RODRIGUES, Rui. História, fontes e caminhos da educação e da cultura. In: CAVALCANTE, Maria Juraci Maia et al. (Org.). Escolas e culturas: políticas, tempos e territórios de ações educacionais. Fortaleza: UFC, 2009. p. 422-441.

MARTINHO RODRIGUES, Rui. Teorias, fontes e período na pesquisa histórica. In: CAVALCANTE, Maria Juraci Maia et al. (Org.). História da educação - vitrais da memória: lugares, imagens e práticas culturais. Fortaleza: UFC, 2008. p. 435-454.

MARTINHO RODRIGUES, Rui. Pesquisa acadêmica: como facilitar o processo de preparação de suas etapas. São Paulo: Atlas, 2007.

MORAIS, Regis de. Filosofia da ciência e da tecnologia: introdução metodológica e crítica. 5. ed. Campinas: Papirus, 1988.

MOTA, Myriam Becho; BRAICK, Patrícia Ramos. História: das cavernas ao Terceiro Milênio. São Paulo: Moderna, 1997.

POPPER, Karl. A lógica da pesquisa científica. São Paulo: Cultrix, 1972.

POPPER, Karl. Conjecturas e refutações. Brasília, DF: UnB, 1982.

QUEIROZ, Tânia Dias. Dicionário prático de pedagogia. São Paulo: Rideel, 2003.

RIBEIRO, Paulo Rodrigues. A História científica do século XIX. In: ALENCAR, Maria Amélia Garcia de (Org.). A história da história. Goiânia: UEG, 2005. p. 43-64.

SOUSA, Raylane Marques; CHAGAS, Eduardo F. Nietzsche, o intempestivo: sobre os excessos da história científica e o não-histórico. Revista Dialectus, Fortaleza, v. 4, n. 10, p. 232-247, 2017. DOI: https://doi.org/10.30611/2017n10id19931. Disponível em: http://periodicos.ufc.br/dialectus/article/view/19931/30572. Acesso em: 2 out. 2020.

TRIVIÑOS, Augusto Nibaldo Silva. Introdução à pesquisa em ciências sociais: a pesquisa qualitativa em educação. São Paulo: Atlas, 1987.

XAVIER, Antônio Roberto; FIALHO, Lia Machado Fiuza; VASCONCELOS, José Gerardo. História, memória e educação: aspectos conceituais e teórico-metodológicos. Fortaleza: UECE, 2018.

\begin{tabular}{|l|l|l|l|l|}
\hline Qovista Dialectus & Ano 10 & n. 23 & Maio - Agosto 2021 & p. 83 - 104 \\
\hline
\end{tabular}

